\title{
Phase Behavior of Poly(ethylene-co-vinyl alcohol)/Nylon 6-12 Blends
}

\author{
Isamu AkIBA and Saburo AkIYAma \\ Laboratory of Chemistry, Faculty of General Education, \\ Tokyo University of Agriculture and Technology, \\ 3-5-8, Saiwai-cho, Fuchu-shi, Tokyo 183, Japan
}

(Received May 24, 1993)

\begin{abstract}
Phase behavior of blends of poly(ethylene-co-vinyl alcohol) containing $59 \mathrm{~mol} \%$ of ethylene units (EVOH59) with nylon 6-12 (PA6-12) containing $60 \mathrm{~mol} \%$ of nylon 6 units was investigated by cloud point measurements and dynamic mechanical measurements. From the results, lower critical solution temperature (LCST) type phase behavior was found in EVOH59/PA6-12 blends above apparent melting points. To account for this, melting point depression was applied to EVOH59/PA6-12 blends to estimate the interaction parameter, $\chi$, between EVOH59 and PA6-12. The estimated value of $\chi$ was -0.58 .

KEY WORDS Blends / LCST Phase Behavior / Poly(ethylene-co-vinyl alcohol) / Nylon 6-12 / Melting Temperature Depression / $\chi$ Parameter /
\end{abstract}

In the last decades, advanced investigations of polymer blends have reported that induced synergistic properties of polymer blends are attributed to miscibility and phase separated structure. ${ }^{1-4}$ Phase separated structures of polymer blends can be controlled by using phase diagram. Therefore, investigation of miscibility and phase behavior in polymer blends have great importance for polymer technology. To interpret miscibility and phase behavior in polymer blends, Flory-Huggins interaction parameter, $\chi$, has great importance because of negligible small value of combinatorial entropy of mixing arisen from high value of degree of polymerization in each polymer components.

Several methods for direct determination of $\chi$ parameter have been proposed such as melting temperature depression, ${ }^{5}$ small angle neutron scattering, ${ }^{6}$ gas-liquid chromatography, ${ }^{7}$ vapor sorption ${ }^{8}$ and ellipsometory. ${ }^{9}$ Among these, melting temperature depression is readily adaptable to a binary polymer mixtures containing crystalline polymer as one of its components. Melting temperature depression method for determination of $\chi$ parameter was applied to polymer blends by Nishi and Wang and several studies concerned with this method have been published ${ }^{10}$ to determine $\chi$ parameter.

In this study, phase behavior of blends of poly(ethylene-co-vinyl alcohol) containing 59 mol\% of ethylene units (EVOH59) with copolyamide constructed by nylon 6 and nylon 12 units containing $60 \mathrm{~mol} \%$ of nylon 6 units (PA6-12) was investigated by cloud point measurements and dynamic mechanical measurements. $\chi$ for EVOH59/PA6-12 blends was determined by melting temperature depression method. Although both EVOH59 and PA6-12 were crystalline polymers, this method may be applied to this system using a temperature region where either EVOH59 or PA6-12 is crystallized.

Since poly(ethylene-co-vinyl alcohol) (EV$\mathrm{OH})$ has excellent gas barrier properties, they have been applied to packages. ${ }^{11,12}$ Especially, blends or composites of EVOH and nylon are used for tubes because the materials constructed from these polymers are strong enough to 
withstand deformation. ${ }^{11}$ Therefore, studies of EVOH/nylon blends or composites such as on miscibility are important. However, studies on EVOH have been mainly concerned with crystalline structure ${ }^{13-16}$ and study on miscibility in blends including EVOH has not been reported. Therefore, study on miscibility of $\mathrm{EVOH} /$ nylon blends should indicate fundamental properties for technology of wrapping.

\section{EXPERIMENTS}

\section{Samples}

Poly(ethylene-co-vinyl alcohol) containing $59 \mathrm{~mol} \%$ of ethylene units (EVOH59) was supplied by Kuraray Co., Ltd. Nylon 6-12 containing $60 \mathrm{~mol} \%$ of nylon 6 units (PA6-12) was purchased from EMS Japan Co., Ltd. Properties of each polymers are listed in Table I. In this table, the values of thermal expansivity of EVOH59 and PA6-12 in melt state were determined by the density gradient method and dilatometer.

\section{Preparation of Blend Samples}

For cloud point measurements and differential scanning calorimetry (DSC), blend samples were prepared by solution mixing. In solution mixing, each polymers were dissolved in hexafluoroisopropanol at about $5 \mathrm{wt} \%$ of polymer concentration and stirred overnight. Solution were cast on glass plates and then placed at room temperature for a day. As-cast films, after placed at room temperature, were seasoned under vacuum at $80^{\circ} \mathrm{C}$ for a week.

For dynamic mechanical measurements, polymers were mixed mechanically using a roller mixer (Nitto Hannoki Seisakusho Co., Ltd.) at $180^{\circ} \mathrm{C}$ and then molded by hot-press at $180^{\circ} \mathrm{C}$ to prepare the test pieces.

Before measurements, all samples were annealed above melting temperature for $2 \mathrm{~h}$ to remove any internal strain of the samples.

\section{Dynamic Mechanical Measurements}

Dynamic mechanical measurements were carried out in a tension mode at $0.01 \mathrm{~Hz}$ of frequency and $1 \mathrm{deg} \min ^{-1}$ of heating rate by using Seiko Instruments Inc. Rheol. Station SDM $5600 \mathrm{H}$ system equipped with DMS-200. Before measurements, samples were annealed at 150 or $170^{\circ} \mathrm{C}$ for $2 \mathrm{~h}$ and then quenched in liquid $\mathrm{N}_{2}$.

\section{Cloud Point Measurements}

Cloud points were measured using a hand made thermo-photometer ${ }^{17-19}$ equipped with CHINO KP-1131 temperature controller in heating process with various heating rate. A He-Ne gas laser (Spectra Physics Model 105-1) of wave length $632.8 \mathrm{~nm}$ was used as the light source. A laser beam was applied vertically to the film samples and transmitted light intensity was detected by photo diode.

\section{Melting Point Measurements}

Samples, after annealed at $170^{\circ} \mathrm{C}$ for $2 \mathrm{~h}$, were quenched to desired crystallization temperature $\left(T_{\mathrm{c}}\right)$ and kept at $T_{\mathrm{c}}$ for several hours. Melting temperature $\left(T_{\mathrm{m}}\right)$ was measured by a Du Pont 990 thermal analyzer equipped with 910 DSC. Since heating rate dependence of $T_{\mathrm{m}}$ was not observed in EVOH59, measurements for the other samples

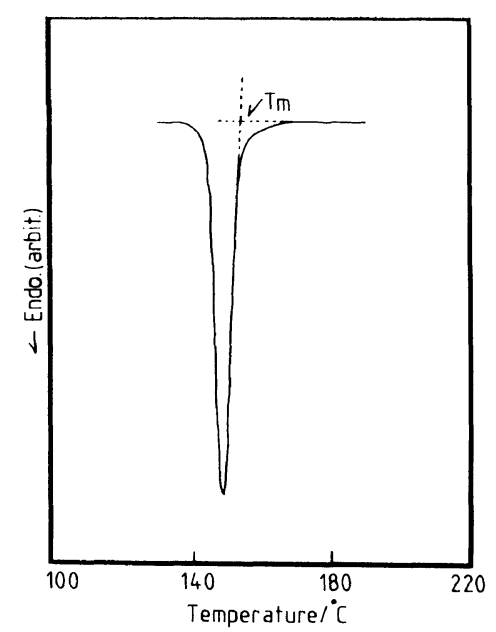

Figure 1. DSC thermogram of EVOH59/PA6-12 90/10 blends around the melting temperature of EVOH59. 
were carried at $10 \mathrm{deg} \mathrm{min}^{-1}$ of heating rate. $T_{\mathrm{m}}$ 's of all the samples were determined as shown in Figure 1.

\section{RESULTS AND DISCUSSION}

Miscibility and Lower Critical Solution Temperature (LCST) Behavior

In Figure 2, plots of $\tan \delta$ spectra corresponding to glass transition region for EVOH59/ PA6-12 blends annealed at $150^{\circ} \mathrm{C}$ are shown. As shown in Figure 2, a single peak indicating miscibility appeared in EVOH59/PA6-12 blends throughout the entire composition range. This suggest that EVOH59/PA6-12 blends are miscible at $150^{\circ} \mathrm{C}$. Similar spectra for EVOH59/PA6-12 50/50, 60/40, and 70/30 blends annealed at $170^{\circ} \mathrm{C}$ are shown in Figure 3. As shown in Figure 3, double peaks which indicate that phase separation occurred in these blends are observed. Resultant $T_{\text {Dmax }}$, the temperature giving the maximum $\tan \delta$ peak in Figure 2, are plotted against blend composition in Figure 4. In this figure, filled circles symbolize $T_{\text {Dmax }}$ 's obtained from Figure 2 and solid line, the composition dependence of $T_{\text {Dmax }}$ predicted by following Fox equation, ${ }^{20}$

$$
1 / T_{\mathrm{Dmax}}=W_{1} / T_{\mathrm{D} \max 1}+W_{2} / T_{\mathrm{D} \max 2}
$$

where $W_{1}$ and $W_{2}$ represent weight fraction and $T_{\mathrm{Dmax} 1}$ and $T_{\mathrm{Dmax} 2}$ represent $T_{\mathrm{Dmax}}$ of

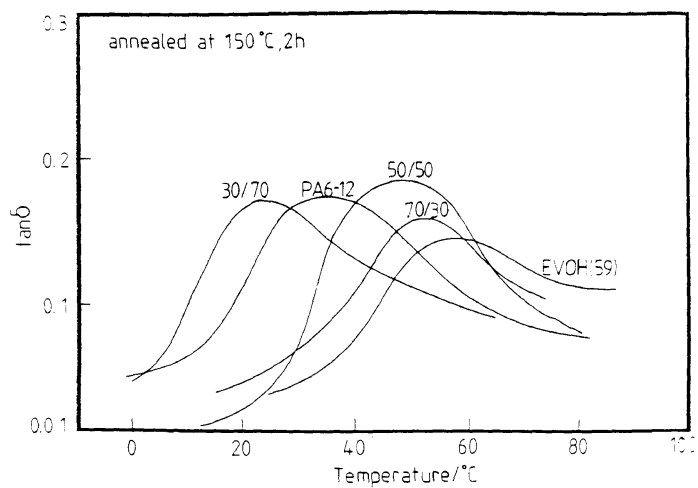

Figure 2. Plots of $\tan \delta$ against temperature for $\mathrm{EVOH}$ $59 /$ PA6 -12 blends annealed at $150^{\circ} \mathrm{C}$ for $2 \mathrm{~h}$. components 1 and 2 , respectively. $T_{\text {Dmax }}$ 's change along the solid line in Figure 4. In general, eq 1 is used for prediction of $T_{\mathrm{g}}$ variation of random copolymers against copolymer composition. Therefore, it is concluded that EVOH59/PA6-12 blends are miscible in the molten state in overall blend composition at $150^{\circ} \mathrm{C}$. Therefore, it was suggested that EVOH59/PA6-12 blends show LCST type phase behavior. Therefore, EVOH59/PA6-12 50/50 blend has LCST around

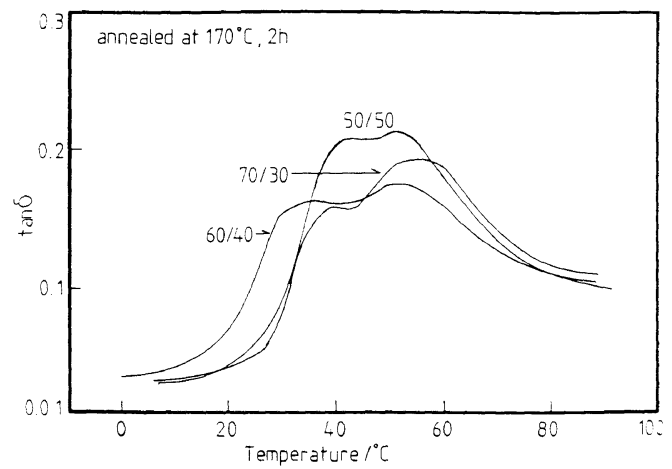

Figure 3. Plots of $\tan \delta$ against temperature for EVOH$59 /$ PA6 -12 blends annealed at $170^{\circ} \mathrm{C}$ for $2 \mathrm{~h}$.

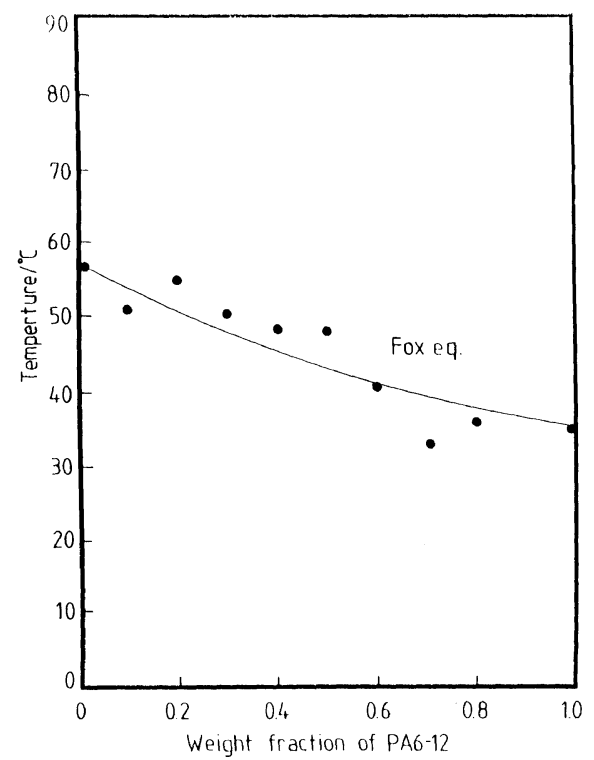

Figure 4. Composition dependence of $\mathrm{Tg}$ of EVOH59/ PA6-12 blends annealed at $150^{\circ} \mathrm{C}$ for $2 \mathrm{~h}$. Composition dependence of $T_{\mathrm{g}}$ follows the Fox equation. 


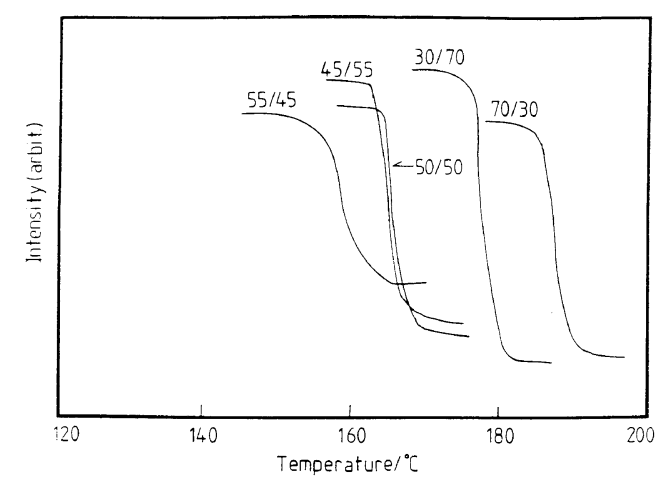

Figure 5. Plots of transparent light intensity against temperature for EVOH59/PA6-12 blends.

$160^{\circ} \mathrm{C}$. Cloud point measurements were made using a handmade thermo-photometer.

In general, transmitted light intensity dramatically changes around liquid-liquid phase transition temperature since light is scattered by samples at two phase region of phase diagram. ${ }^{19}$ Some plots of transmitted light intensity versus temperature are shown in Figure 5. It can be seen in Figure 5 that transmitted light intensity decreases with temperature. The temperature at which transmitted light intensity decreased is close to the temperature where heterogeneous phase structure appeared in morphological observation. Therefore, decrease of transmitted light intensity with increasing temperature comes from LCST phase behavior. Cloud points were determined following the previous study. ${ }^{17-19}$ In general, cloud points obtained in heating process depend on heating rate because phase separation is a time-dependent process. ${ }^{22}$ In Figure 6 , heating rate dependency of cloud points in EVOH59/PA6-12 55/45 blends are shown. It can be seen that heating rate dependency of cloud points in this system is negligible. This means that liquid-liquid phase transition in this system is fast. However, since resultant cloud points showed weak dependency on heating rate, real cloud points were determined as points of extrapolation of least square straight line between cloud points and

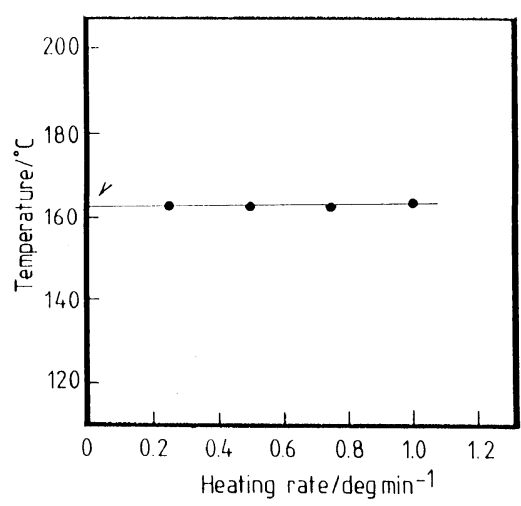

Figure 6. Heating rate dependence of cloud points in EVOH59/PA6-12 50/50 blends. Solid line is least square straight line between cloud points and heating rate.

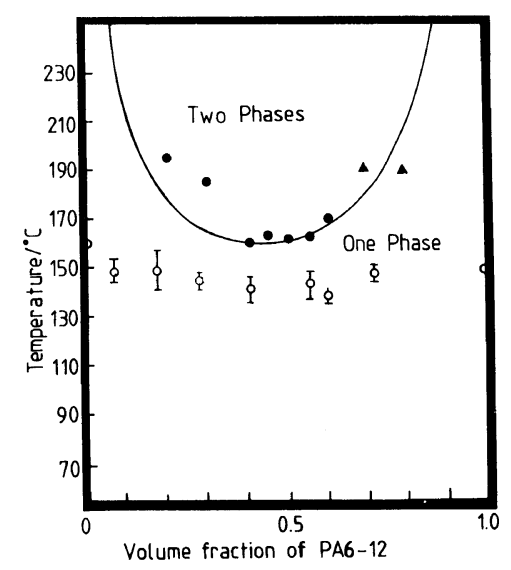

Figure 7. LCST phase diagram of EVOH59/PA6-12 blends. Closed circles are cloud points and open circles, apparent melting temperature.

heating rate to $0 \mathrm{deg} \min ^{-1}$. Resultant cloud points are plotted against blend composition in Figure 7. In this figure, filled circles represent cloud points and open circles, apparent melting points of the blends obtained by DSC. The cloud point curve was typical of the LCST type phase diagram. The miscible region of EVOH59/PA6 - 12 blends was narrow above the apparent melting temperature. The blends of EVOH containing 0, 32, 44, 72, and 100 $\mathrm{mol} \%$ of ethylene units with PA6-12 were also investigated. ${ }^{23}$ It was found that these systems were immiscible from apparent melting tem- 
perature to thermal degradation temperature and liquid-liquid phase transition behavior of these systems has never appeared except in EVOH59/PA6-12 blends. EVOH/PA6-12 blends may thus be immiscible in melt state because melting temperature in $\mathrm{EVOH}$ of lower ethylene unit contents is too high and intermolecular interactions between $\mathrm{EVOH}$ with higher ethylene unit contents and PA6-12 are too weak to show miscibility in the region between the apparent melting temperature and thermal degradation temperature of these systems.

\section{Melting Temperature Depression}

Since LCST type phase behavior was observed in EVOH59/PA6-12 blends as mentioned above, intermolecular interactions between these polymers may be strong. Therefore, Flory-Huggins interaction parameter, $\chi$, should play an important role.

For estimation of $\chi$ in EVOH59/PA6-12 blends, analysis of melting temperature depression was made for EVOH59/PA6-12 blends. In general, this analysis has been made for the blends which include crystalline polymer as one of its components. Since EVOH59 and PA6-12 are crystalline polymers, melting temperature depression can be made for the blends to estimate $\chi$.

According to Hoffman and Weeks' analysis, ${ }^{24,25}$ apparent melting temperature is expected to follow a linear relationship with isothermal crystallization temperature such as;

$$
T_{\mathrm{m}}{ }^{0}-T_{\mathrm{m}}=\psi\left(T_{\mathrm{m}}{ }^{0}-T_{\mathrm{c}}\right)
$$

where $T_{\mathrm{m}}$ is the resultant apparent melting temperature after isothermal crystallization at $T_{\mathrm{c}}, \psi$ is a stability parameter which has dependency on the thickness of crystal. $T_{\mathrm{m}}{ }^{0}$ is the equilibrium melting temperature estimated by extrapolation of straight line following eq 2 to $T_{\mathrm{m}}=T_{\mathrm{c}}$ in plots of $T_{\mathrm{m}}$ versus $T_{\mathrm{c}}$. In Figure 8, some Hoffman-Weeks plots for EVOH59/PA6 - 12 blends are shown. In this figure, filled circles are resultant $T_{\mathrm{m}}$ after

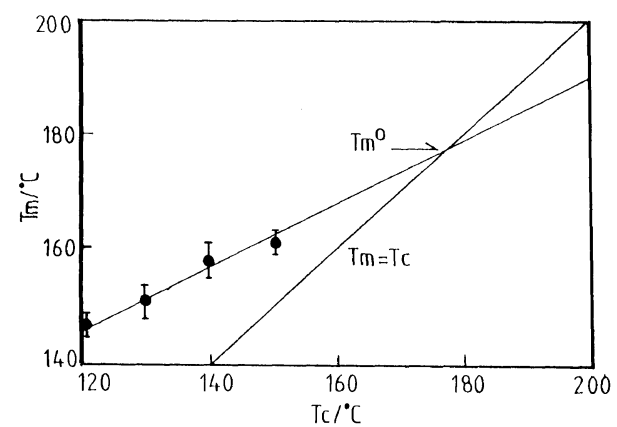

Figure 8. Hoffman-Weeks plots of EVOH59/PA6-12 $9 / 1$ blends.

Table I. Table 1 Properties of EVOH59 and PA6-12

\begin{tabular}{lrrrr}
\hline Samples & $\mathrm{DP}^{\mathrm{a}}$ & $T_{\mathrm{g}} /{ }^{\circ} \mathrm{C}^{\mathrm{b}}$ & $T_{\mathrm{m}} /{ }^{\circ} \mathrm{C}^{\mathrm{b}}$ & $\begin{array}{c}\text { Thermal } \\
\text { expansivity } \\
\text { (in melt state) }\end{array}$ \\
\hline EVOH59 & 680 & 31.0 & 159.0 & $6.264 \times 10^{-4}$ \\
PA6-12 & 1200 & 29.0 & 146.0 & $6.993 \times 10^{-4}$ \\
\hline
\end{tabular}

a DP represents degree of polymerization.

$b$ Values were obtained from DSC measurements.

Table II. Equilibrium melting temperature and stability parameter, $\psi$, of EVOH59/PA6-12 blends

\begin{tabular}{lll}
\hline $\begin{array}{c}\text { Volume fraction of } \\
\text { PA6-12 }\end{array}$ & $T_{\mathrm{m}}{ }^{0}$ & $\psi$ \\
\hline 0 & 181.8 & 0.566 \\
0.047 & 179.4 & 0.485 \\
0.095 & 177.0 & 0.550 \\
0.143 & 173.6 & 0.517 \\
0.191 & 170.4 & 0.414 \\
\hline
\end{tabular}

annealing at $T_{\mathrm{c}}$ and solid lines are least square straight lines for experimental data. The error bars are experimental error. Following eq 2, equilibrium melting temperature was determined by extrapolation of such straight line to $T_{\mathrm{m}}=T_{\mathrm{c}}$. Resultant equilibrium melting temperature, $T_{\mathrm{m}}{ }^{0}$, and stability parameter, $\psi$, for EVOH59/PA6-12 blends are listed in Table II. In Table II, $T_{\mathrm{m}}{ }^{0}$ 's are decreasing with increasing content of PA6-12 in EVOH59/ PA6 - 12 blends. In addition, $\psi$ 's of EVOH59/ PA6-12 blends are close to each other as 
shown in Table II. Hence, melting temperature depression in EVOH59/PA6-12 blends occurred without effect of crystal structure. Nishi and Wang derived a relationship between equilibrium melting temperature and blend composition for polymers of infinite molecular weight on the basis of Flory-Huggins theory as following equation, ${ }^{5}$

$$
1 / T_{\mathrm{m} \text { blend }}^{0}-1 / T_{\mathrm{m}}{ }^{0}=-R V_{2} / \Delta H_{2 \mathrm{u}} V_{1} \chi_{12} \phi_{1}{ }^{2}
$$

where $T_{\mathrm{m}}{ }^{0}$ blend is the equilibrium melting temperature for blends, $T_{\mathrm{m}}{ }^{0}$ is the value for a pure component, $\Delta H_{2 \mathrm{u}}$ is the heat of fusion permole of repeating units for crystalline component, $V_{1}$ and $V_{2}$ are molar volumes of the repeating units for amorphous and crystalline component, respectively, $\phi_{1}$ is volume fraction of amorphous component, $R$ is gas constant and $\chi_{12}$ is an interaction parameter. They applied eq 3 to poly(vinylidene fluoride)/polystyrene blends which show LCST type phase behavior. By eq 3 , a plot of $1 / T_{\mathrm{m}}{ }^{0}$ blend $-1 / T_{\mathrm{m}}{ }^{0}$ against $\phi_{1}{ }^{2}$ should give a straight line across the original point with a slope of $\chi_{12}$. Plots of the left side in eq 3 versus $\phi_{\text {PA6-12 }}{ }^{2}$ are shown in Figure 9 . The error bars in Figure 9 are experimental error in $T_{\mathrm{m}} \mathrm{s}$. The following parameter values were used in our calculation: $\Delta H_{2 \mathrm{u}}=4.22 \mathrm{kJmol}^{-1}, V_{1}=29.79$ $\mathrm{cm}^{3} \mathrm{~mol}^{-1}, V_{2}=37.80 \mathrm{~cm}^{3} \mathrm{~mol}^{-1}$. Using these values, the value of $\chi_{12}$ is estimated as -0.58 . There thus may be comparatively strong intermolecular interactions between EVOH59 and PA6-12. However, since the straight line does not pass through the original point, $\chi_{12}$ is not reliable. This may be due to the contribution of composition dependence of $\chi_{12}{ }^{26,27}$ and/or morphological effects of crystalline structure to $T_{\mathrm{m}},{ }^{28,29}$ not taken into account in eq 3 .

\section{CONCLUSION}

From the results of cloud point measurements, morphological observation and $\tan \delta$

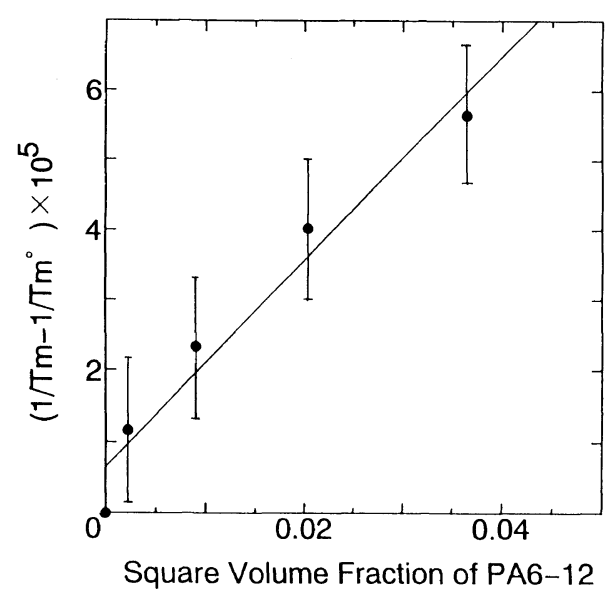

Figure 9. Plots of left hand side of eq 3 against volume fraction of PA6-12 in EVOH59/PA6-12 blends.

behavior in dynamic mechanical measurements, LCST type phase behavior of EVOH59/ PA6-12 blends was found in a narrow temperature region between the apparent melting temperature and thermal degradation temperature of this system. Since composition dependence of $T_{\text {Dmax }}$ for EVOH59/PA6-12 blends annealed at $150^{\circ} \mathrm{C}$ followed the Fox equation, the blends were shown to be miscible in the molten state in the overall blend composition range at $150^{\circ} \mathrm{C}$.

Using the analysis of melting temperature depression, the Flory-Huggins interaction parameter, $\chi$, for EVOH59/PA6-12 blends was estimated as -0.58 suggesting that there were comparatively strong intermolecular interactions between EVOH59 and PA6-12.

Acknowledgment. The authors would like to express their gratitude to Dr. S. Kawahara of Tokyo University of Agriculture and Technology for their helpful comments, and to Dr. Y. Tanaka of Kuraray Co., Ltd. for supplying the EVOH samples.

\section{REFERENCES}

1. D. R. Paul and S. Newman, Ed.,"Polymer Blends," Vols. 1 and 2, Academic Press, New York, 1978. 
2. S. Akiyama, T. Inoue, and T. Nishi, "Polymer Blends - Compatibility and Interface" (in Japanese), CMC Press, Tokyo, 1979 (R\&D report).

3. O. Olabisi, L. M. Robeson, and M. T. Shaw, "Polymer-Polymer Miscibility," Academic Press, New York, 1979.

4. L. A. Utracki, "Polymer Alloys and BlendsThermodynamics and Rheology-," Carl Hanser, 1989.

5. T. Nishi and T. T. Wang, Macromolecules, 8, 909 (1975).

6. W. A. Kruse, R. G. Kirste, J. Haas, B. J. Schmitt, and D. J. Stein, Macromol. Chem., 177, 1145 (1976).

7. O. Olabisi, Macromolecules, 8, 316 (1975).

8. T. K. Kwei, T. Nishi, and R. F. Roberts, Macromolecules, 7, 667 (1974).

9. N. Higashida, J. Kressler, S. Yukioka, and T. Inoue, Macromolecules, 25, 5259 (1992).

10. S. Rostami, Polymer, 31, 899 (1990).

11. Y. Tanaka, Jpn. Food Sci., 7, 49 (1989).

12. H. Iwasaki and K. Hoashi, Kobunshi Ronbunshu, 34, 785 (1977).

13. T. Matsumoto, K. Nakamae, N. Ogoshi, M. Kawazoe, and H. Oka, Kobunshi Kagaku, 28, 610 (1971).

14. T. Matsumoto, K. Nakamae, H. Oka, S. Kawarai, and T. Ochiumi, Sen-i Gakkaishi, 31, T-152 (1975).

15. H. Yoshida, H. Kanbara, N. Takemura, and Y.
Kobayashi, Sen-i Gakkaishi, 39, T-512 (1983).

16. S. Ramakrishnan, Macromolecules, 24, 3753 (1991).

17. S. Akiyama and R. Kaneko, Kobunshi Ronbunshu, 25, 487 (1974).

18. M. Hasegawa and S. Akiyama, Polym. J., 20, 471 (1988).

19. S. Akiyama, K. Ishikawa, and H. Fujiishi, Polymer, 32, 1673 (1991).

20. T. G. Fox, Bull. Am. Phys. Soc., 1, 123 (1956).

21. T. Nishi, T. T. Wang, and T. K. Kwei, Macromolecules, 8, 227 (1975).

22. T. Kyu and J. M. Saldanha, J. Polym. Sci., C, Polym. Lett., 26, 33 (1988).

23. S. Akiyama and I. Akiba, Polym. Prepr., Jpn., 41, 911 (1992).

24. J. D. Hoffman and J. J. Weeks, J. Res. Natl. Bur. Stand., Sect. A, 66, 13 (1962).

25. L. Mandelkern, "Crystallization of Polymers," McGraw-Hill, New York, N. Y., 1964.

26. S. Kawahara and S. Akiyama, Bull. Fac. Gen. Educ. Tokyo Univ. Agric. \& Tech., 28, 111 (1991).

27. P. C. Painter, S. L. Shenoy, D. E. Bhagwager, J. Fishburn, and M. M. Coleman, Macromolecules, 24, 5623 (1991).

28. T. K. Kwei and H. L. Frisch, Macromolecules, 11, 1267 (1978).

29. S. Cimmino, E. Martuscelli, and C. Silvestre, $J$. Polym. Sci., B, Polym. Phys. Ed., 27, 1781 (1989). 